Journal of Engineering and Applied Sciences 14 (15): 5064-5071, 2019

ISSN: 1816-949X

(C) Medwell Journals, 2019

\title{
Optimize Neural Network for Maritime Weather
}

\author{
Wimala L. Dhanistha, Herman Pratikno and Wisnu Wardhana \\ Departement of Ocean Engineering, Institute Technology Sepuluh Nopember, East Java, Indonesia
}

\begin{abstract}
Indonesia is an archipelagic country a more reliable transportation is a type of sea transportation. One of the obstacles in transportation is that $38 \%$ of the causes of marine accidents are high-wave natural disasters caused by wind speeds. The higher the wind speed, the higher the wave will occur. Artificial neural networks are artificial intelligence that can be used to predict high waves. These neural networking advantages can be used for nonlinear systems. Neural networks can be used as high-wave predictors to predict the wave height of the last few hours to come.
\end{abstract}

Key words: High waves, wind speed, artificial neural network, transportation, artificial, predictors

\section{INTRODUCTION}

Indonesia is an archipelago country, therefore, the sea transportation has an important role in the economic sector of Indonesia. Waves are one of the important factors for shipping. Waves can be beneficial and detrimental. A favorable wave can help the ship sail while dangerous waves can sink the ship then for wave height information before sailing is important in marine transport. Factors causing sea transport accidents to happen include $41,38 \%$ force majeure and $21 \%$ due to ship damage (Sugianto, 2012). Mentioned one cause of the accident is a high-force force majeure. High wave of information is needed for shipping reference (Paras et al., 2007). Indonesian Meteorology, Climatology and Geophysics Agency (BMKG) using conventional methods (statistics and dynamics) for wave height prediction.

Neural Network (NN) was one of Artifical Intelligence (AI) algorithm. Excess neural network have black box can capable of studying the relations about input-output system, so, it does not require mathematical calculations by overcoming Dhanistha et al. (2017). Opinions others say artificial neural network involves the information distribution parallel and be able to manage nonlinear systems (Paras et al., 2007). Research studies about artificial neural network to predict Rainfall (RF) and Relative Humidity $(\mathrm{RH})$ using multi layer (Peres et al., 2015) an algorithm artificial neural network can predict better than algorithms nlarx (Aisjah et al., 2016), compare predictions use artificial neural network and regression method (Agrawal and Deo, 2004), predictions wave height by wind speed and the waves on an hour before (Paplinska-Swerpel and Paszke, 2006) and wave height prediction used backpropagation method (Makarynskyy et al., 2004).

The Java Sea chosen as the prediction because the Java Sea including one of the most populous in Indonesia, so, information about the waves is important to see earlier as well as expected this research can reduce the crash at sea transport particularly wave height. Information of waves is takes at sea transport. The fluid dynamic has distinctive patterns that can be formulated mathematically. One of the causes of the wave height is wind (Triatmodjo, 1999).

In previous research, it has been proven that artificial neural networks predict wave heights because artificial neural networks have black boxes capable of solving nonlinear systems (Makarynskyy et al., 2004). The main factor affecting wave heights is wind. The faster the wind, the greater the wave height (Mandal, 2010; Sutojo et al., 2010), so that, in this study wind will be used as input predictor. In the design of ANN, used 3 input layers of the current wave height (Hst), wave heights $1 \mathrm{~h}$ ago (Hst-1) and wind speed. The hidden layer is 7 and the output layer is 1 (Hs) with an iteration of 2000 (Paplinska-Swerpel and Paszke, 2006). Predicted wave heights using artificial Neural Networks yields a better RMSE than NLARX (Dhanistha et al., 2017). Backpropagation is used to train the ANN with 80 training and $20 \%$ validation, the predicted result is quite accurate with the average RMSE of 0.15 for the $3 \mathrm{~h}$ wave height (Jain and Deo, 2008) using the same training and input, the correlation R BMKG data wave height with a prediction of 0.93 (Gunaydyn, 2008).

Corresponding Author: Wimala L. Dhanistha, Departement of Ocean Engineering, Institute Technology Sepuluh Nopember, East Java, Indonesia 


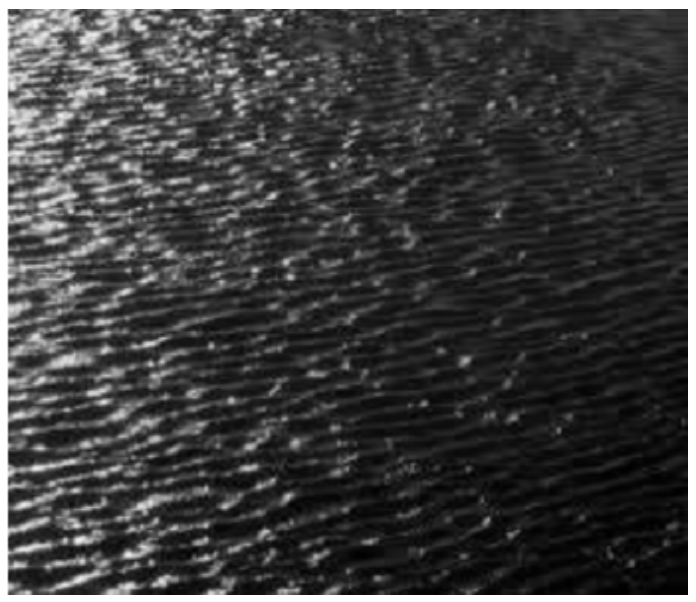

Fig. 1: Ripples (Bhattacharya et al., 2003)

A wind blows above the surface of water it will move the energy he would had on the water (Dhanistha et al., 2017). Wind that blows in the sight of ripple shown in Fig. 1 and will develop into the waves and high places its new wave. The greater velocity of the wind blows then would be more greater likelihood a wave (Akhir and Mera, 2011). The wind with great speed (hurricane) that goes on upon the surface of the sea can actually roll out large marine fluctuations in the surface of the waters. $\mathrm{H}_{1 / 3}$ is the average $33.3 \%$ highest of wave. $\mathrm{H}_{1 / 3}$ is high of a wave by which used as publicly listed shipping to be a manual and is called also the waves to overcome it Hs. It is used the waves to overcome it has the highest poverty rate due to a round of low there are not many affecting of shipping (Sugiarto, 2012). The wave height is influence variable for the feasibility shipping (Bhattacharya et al., 2003). The criteria for high waves that affect shipping (Dhanistha et al., 2017):

$$
\begin{aligned}
1.25-2.0 \mathrm{~m}= & \text { Harmful to fishing boat } \\
2.0-3.0 \mathrm{~m}= & \text { Harmful to fishing boats and a barge } \\
3.0-4.0 \mathrm{~m}= & \text { Harmful to fishing boat a barge and } \\
& \text { ferry } \\
>4.0 \mathrm{~m} & =\text { Harmful to all ships }
\end{aligned}
$$

\section{MATERIALS AND METHODS}

Neural network: Neural network one of artificial intelligence algorithm with nodes around each and other (Etemad-Shahidi et al., 2009). Node it is attached through the links of a which is called by weight. Artificial neural network is the tissue on which it distributed in parallel (Londhe et al., 2016). The first rudimentary forms a neuron

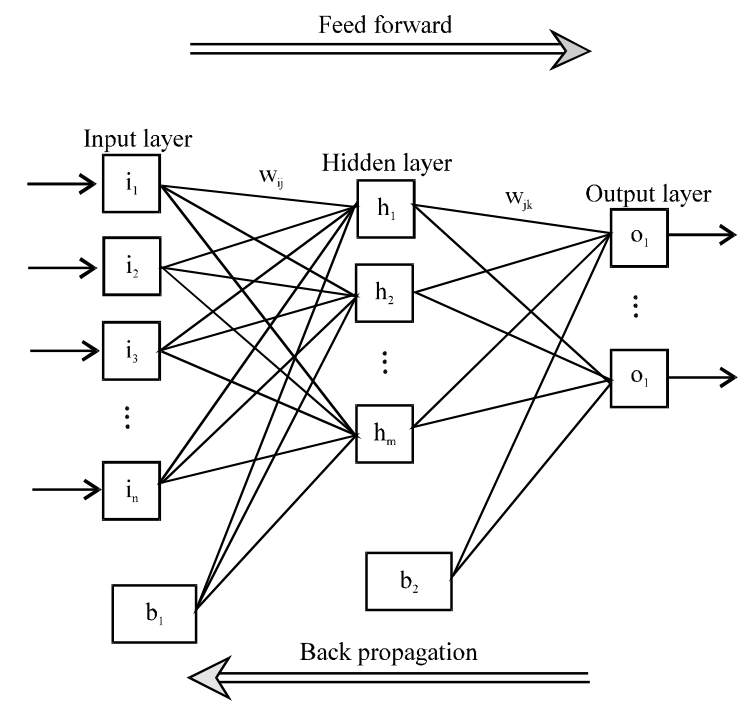

Fig. 2: Based neuron (Gunaydyn, 2008)

there are in Fig. 2. Where is the input is used for training as well as matter of validating, weight is always changing each division of the families of input to student performance review the import facility granted learning, processing unit is the location of the the process of the introduction of an object based on that the weight of that is given to them and output is output of neural network is about (Dhanistha et al., 2017).

Node it is attached through the links of a node which is called by weight. Artificial neural network constitutes (Gunaydyn, 2008). The fundamental forms of neurons there are in Fig. 2. Where input will be used for training and validation, weight are a burden each given a changing input as learning, processing unit is the location of the process of the introduction of an object based on weight that given and output is output of neural network (Dhanistha et al., 2017). The advantages of neural network methods (Gunaydyn, 2008):

Can be used for nonlinear system forecasting

Simplify mapping system output without knowing the process that happened (black-box)

Have the ability to learn a process based on data provided by training (Sutojo et al., 2010)

Be able to represent information received during the training process (Sutojo et al., 2010)

Whether or not a neural network model is determined by Deo and Naidu (1998)

Network architecture which is an architecture that determines patterns between neurons

Learning method which is the method used to determine and change the weights

Activation function

Selection of input (Srivastava, 1964) 


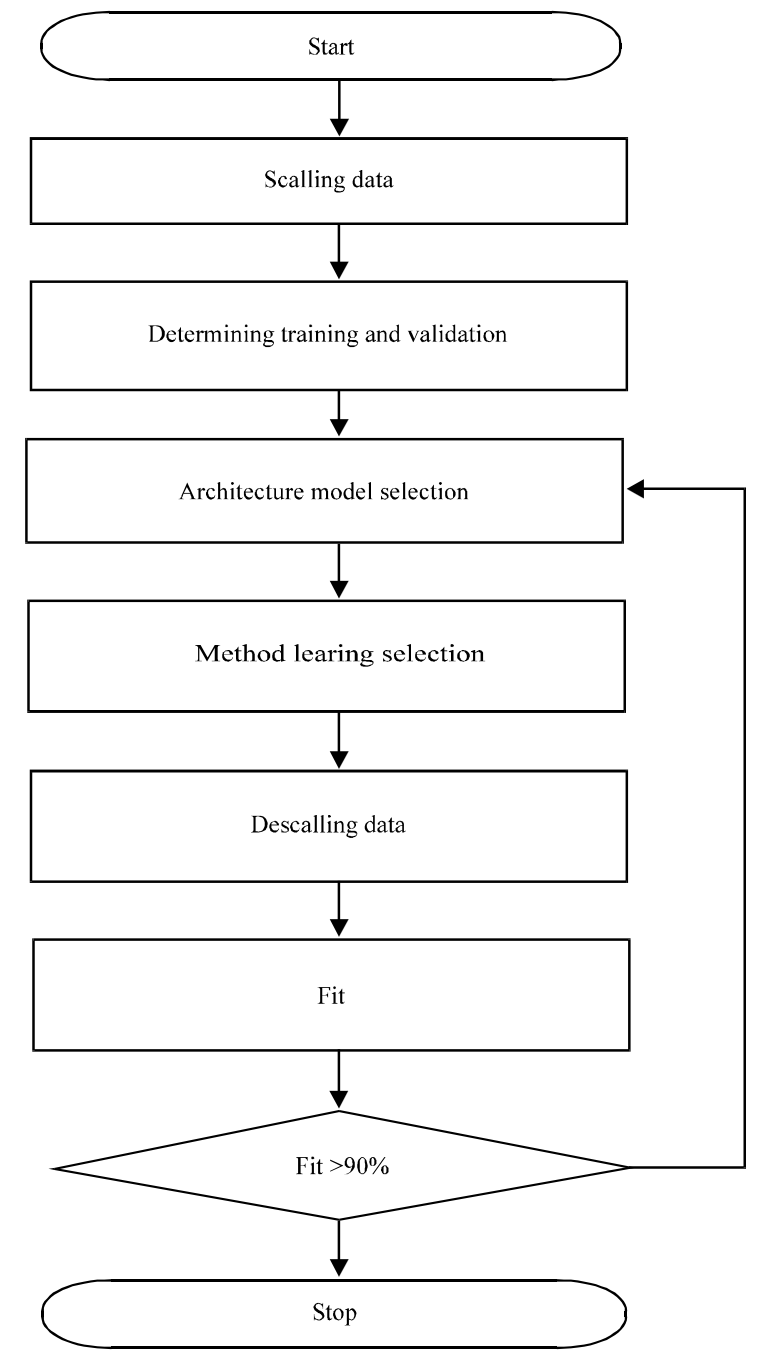

Fig. 3: Flowchart neural network

\section{RESULTS AND DISCUSSION}

Network performance: Performance generated by artificial neural networks will be evaluated using Root Mean Square Error (RMSE) is an indicator of the average error in the analysis (Fig. 3). The smaller the RMSE is generated, the more valid the value of the model (Gunaydyn, 2008):

$$
\operatorname{RMSE}=\sqrt{\frac{\sum_{\mathrm{i}=1}^{\mathrm{N}}\left(\mathrm{y}_{\mathrm{i}}-\mathrm{x}_{\mathrm{i}}\right)^{2}}{\mathrm{~N}}}
$$

Where:

$\mathrm{N}=$ Amount of data

$\mathrm{x}_{\mathrm{i}}=$ Measured

$\mathrm{y}_{\mathrm{i}}=$ Prediction

Data analysis: The location of the data is at point A, point $\mathrm{B}$ and point $\mathrm{C}$. The first point on longitude: $112.747800 \mathrm{E}$ atitude: $6.874824 \mathrm{~S}$ (point A) waters of Surabaya, second on longitude: $113.908800 \mathrm{E}$ latitude: $4.648136 \mathrm{~S}$ (point B) Java Sea and the third on longitude: $114.484300 \mathrm{E}$ latitude: $3.540425 \mathrm{~S}$ (point C) waters of Banjarmasin as shown in Fig. 4. The data collected in the form of wind speed and wave height in Java Sea from 2010 until March 2015. The data is collected based on the data contained in BMKG Perak II Surabaya. After the data obtained then done the design of neural network and GUI to easily read predictions that have been designed after which the results will be analyzed by comparing with previous research.

In Fig. 3, this research for artificial neural networks start by scaling data to equalize the range of inputs and outputs between 0 and 1 . Scalling data needed to speed up convergence during training and validation on identification of artificial neural networks (Arief, 2006). One method that is often used is the min-max method where the method is quite simple but has shortcomings if the new input data exceeds the maximum scaling limit (Aisjah et al., 2016). This method is a scalling method such as in the following equation:

$$
X_{2}=\frac{X_{1}-\operatorname{Min}(X)}{\operatorname{Max}(X)-\operatorname{Min}(X)}
$$

With:

$$
\begin{array}{ll}
\mathrm{X}_{2} & =\text { Scaled data } \\
\mathrm{X}_{1} & =\text { Unscaled data } \\
\operatorname{Min}(\mathrm{X}) & =\text { Minimum data } \\
\operatorname{Max}(\mathrm{X}) & =\text { Maximum data }
\end{array}
$$

This method is essentially the same ie carrying data in the range $0-1$. So that, the distribution of data after discaling is in the range of $0-1$. After processed in the neural network model then the data is returned again in the initial data range is by using the reverse equation of the scalling method (descalling). Descaling is returning the scaling value to its true value. The required data is the minimum and maximum value of initial data as in Eq. 3 (Fig. 4):

$$
\mathrm{X}_{1}=\mathrm{X}_{2}(\operatorname{Max}(\mathrm{X})-\operatorname{Min}(\mathrm{X}))+\operatorname{Min}(\mathrm{X})
$$

After that determine how much data is used for training and validation. Training is used for learning ANN about the relationship between input and output then tested using validation data. The amount of training data is more than the validation data is $80 \%$ of data for training, and $20 \%$ data for validation. After the data sharing and 


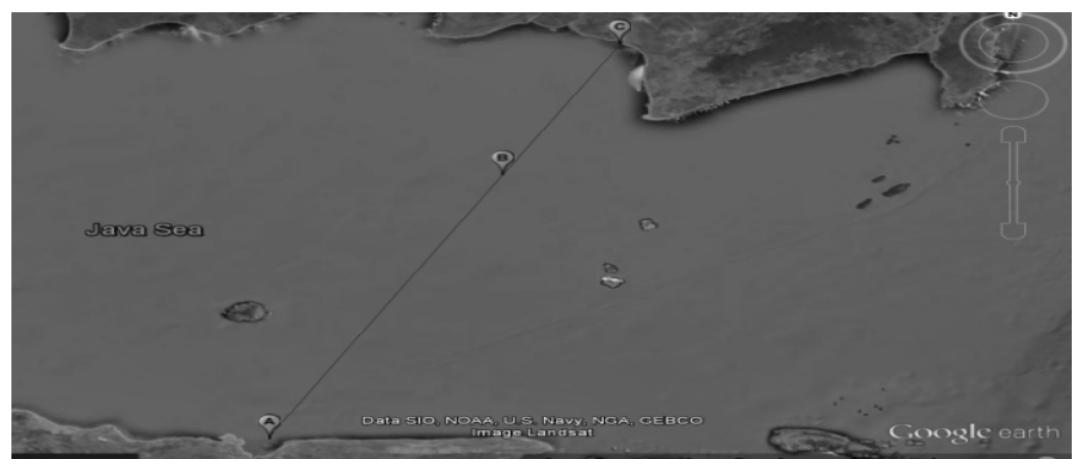

Fig. 4: Location of prediction

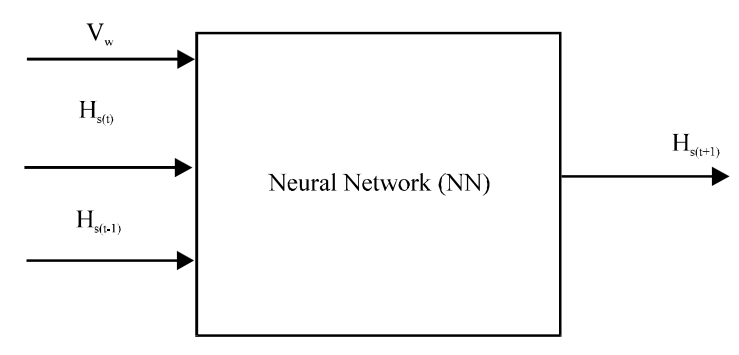

Fig. 5: Block diagram

validation training, the next step is choosing a network architecture. Network architecture uses multiple layers or multi layer perceptron this network consists of 3 layers, namely the input layer, the hidden layer and the output layer. Multiple perceptron or multilayer coatings are selected because these networks are capable of solving more complex problems compared to a single layer (Etemad-Shahidi et al., 2009). After that the learning method using backpropagation. Results obtained at deskaling first or return to the original range. After that new RMSE tested if the fitness is $>90 \%$ or small RMSE below 0.2 then completed if not yet meet will return on the selection of network architecture model. Figure 5 is a block diagram of workmanship, block diagram is used to facilitate the work of input and output used. The predictor input is wind Speed $(\mathrm{Vw}(\mathrm{t}))$, wave height $\left(\mathrm{H}_{s(t)}\right)$ and the previous wave height of $1 \mathrm{~h}\left(\mathrm{H}_{s(t-1)}\right)$ and the predictor output is $\left(\mathrm{H}_{\mathrm{s}(\mathrm{t}+1)}\right)$. In designing this predictor it will change the large hidden layers (1-10) and epoch $(10,100$ and 1000) to obtain the smallest RMSE validation and produce the best predictive weight.

Wind speed: This research, wave height influenced by wind speed. Wind speed and wave height, since, 2010 until 2015 used for input and output data. The smaller the wind speed that blows, the lower the wave height occurs.
Conversely, the greater the wind speed that blows, the higher the wave height occurs (Paplinska-Swerpel and Paszke, 2006). Figure 6 and 7 is a graph of wind speed and wave height that occurred in 2010 until 2015 as many as 46, 016 data. From these two graphs can be seen the relationship between wind speed and wave height where the higher wind speed, the higher wave occurs. Table 1-3 show that high velocity of wind every year in December until February.

Wave height: In addition to wind speed, wave height is also affected by the height of the wave itself at an earlier time. So, this research requires wave height data from 2006 until 2011 as many as 46,016 wave height data. There are three locations of wave height data obtained in the first graph on longitude: $112.747800 \mathrm{E}$ latitude: $6.874824 \mathrm{~S}$ (waters of Surabaya point A) blue, second on longitude: $113.908800 \mathrm{E}$ latitude: $4.648136 \mathrm{~S}$ (sea point $\mathrm{B}$ point) red and third on longitude: $114.484300 \mathrm{E}$ latitude: $3.540425 \mathrm{~S}$ (Banjarmasin waters point C) magenta color. From the graph can be seen that which has the highest wave height that is red (point B) this is because point $B$ is in the middle of the sea. Ground winds blow from land to sea, so, the wind speed in the middle of the sea is greater than in the edge causing the wave height in the middle of the sea is higher than the wave height at the edge (point A).

Table 4 and 5 is the wave height data at each point based on the average per year and maximum wave height per year. Same with wind speed, maximum wave height occurs in December-February which coincides with the rainy season. The hidden layer on the neural network is changed from 1-10 and the epoch is changed to 10,100 and 1000. So as to get the best Root Mean Square Error (RMSE) as in Table 1 for point A, Table 2 for point $\mathrm{B}$ and Table 3 for point $C$. The smallest RMSE on Table 1 is 0.007672 using 3 hidden layers at 10 epoch. The smallest 


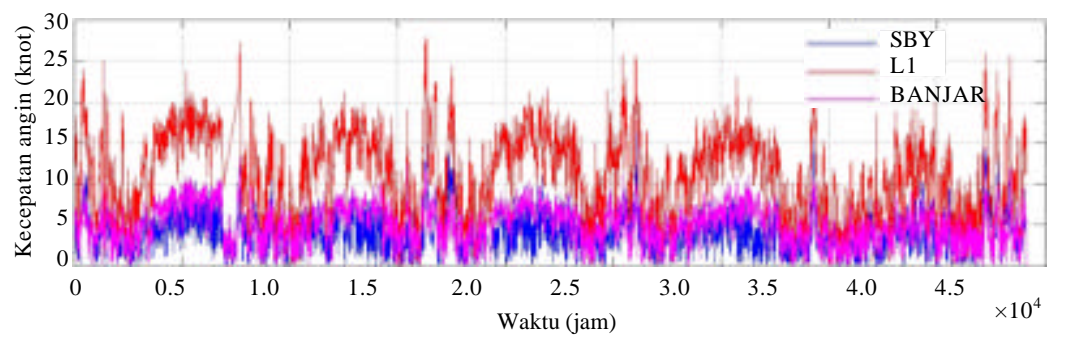

Fig. 6: Wind speed 2010-2015

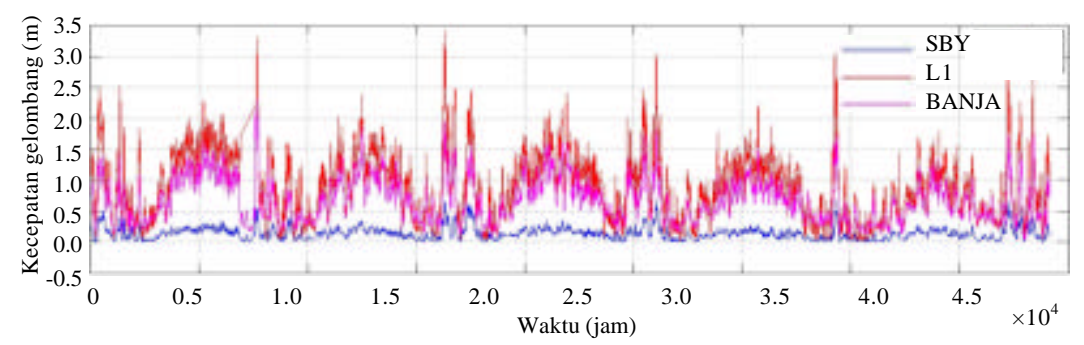

Fig. 7: Wave height 2010-2015

Table 1: Wind speed Surabaya

\begin{tabular}{lllllll}
\hline Variables & 2010 & 2011 & 2012 & 2013 & 2014 & 2015 \\
\hline Average & 3.9 & 3.8 & 4.04 & 3.72 & 4.07 & 6.18 \\
Maximum & 11.06 & 14.89 & 13.86 & 16.81 & 10.19 & 14.35 \\
Date & 25 January & 29 December & 9 February & 7 February & 31 December & 12 January \\
\hline
\end{tabular}

Table 2: Wind speed Java Sea

\begin{tabular}{lllllll}
\hline Variables & 2010 & 2011 & 2012 & 2013 & 2014 & 2015 \\
\hline Average & 12.4 & 10.81 & 11.64 & 8.05 & 6.04 & 10.56 \\
Maximum & 25.04 & 27.92 & 24.38 & 22.77 & 15.98 & 25.94 \\
Date & 27 February & 27 December & 15 February & 9 January & 10 February & 12 January \\
\hline
\end{tabular}

Table 3: Wind speed Banjarmasin

\begin{tabular}{lllllll}
\hline Variables & 2010 & 2011 & 2012 & 2013 & 2014 & 2015 \\
\hline Average & 5.36 & 4.93 & 5.1 & 4.97 & 3.53 & 4.25 \\
Maximum & 11.49 & 13.36 & 10.36 & 11.21 & 10.86 & 12.28 \\
Date & 18 January & 3 January & 8 February & 5 February & 13 January & 12 January \\
\hline
\end{tabular}

Table 4: Wave height Surabaya

\begin{tabular}{lllllll}
\hline Variables & 2010 & 2011 & 2012 & 2013 & 2014 & 2015 \\
\hline Average & 3.9 & 3.8 & 4.04 & 3.72 & 4.07 & 6.18 \\
Maximum & 11.06 & 14.89 & 13.86 & 16.81 & 10.19 & 14.35 \\
Date & 25 January & 29 December & 9 February & 7 February & 31 December & 12 January \\
\hline
\end{tabular}

Table 5: Wave height Java Sea

\begin{tabular}{lllllll}
\hline Variables & 2006 & 2007 & 2008 & 2009 & 2010 & 2011 \\
\hline Average & 1.2 & 0.9 & 0.98 & 0.75 & 0.56 & 0.94 \\
Maximum & 2.51 & 3.42 & 2.48 & 3.04 & 1.4 & 2.92 \\
Date & 27 February & 27 December & 15 February & 9 January & 10 February & 12 January \\
\hline
\end{tabular}

RMSE in Table 2 is 0.004008 using 10 hidden layers at 1000 epoch and the smallest RMSE in Table 3 is 0.003355 using 2 hidden layers at 1000 epoch, that weights will be used to design the predictors (Table 6-9).

After training and validation, this neural network algorithm produces weights that will be used to predict wave heights. Figure 8 and 9 is a graph of wave height prediction of each in Surabaya waters (point A), (Fig. 10). Java Sea (point B) and Fig. 11. Banjarmasin waters (point C). The blue color is the wave height of the BMKG data and the red color is the wave height of the predicted ANN results based on the wind speed, current wave height and 


\section{J. Eng. Applied Sci., 14 (15): 5064-5071, 2019}

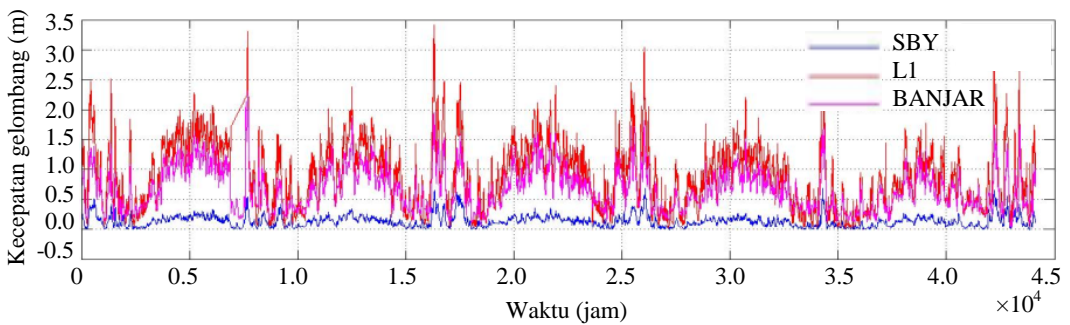

Fig. 8: Wave height

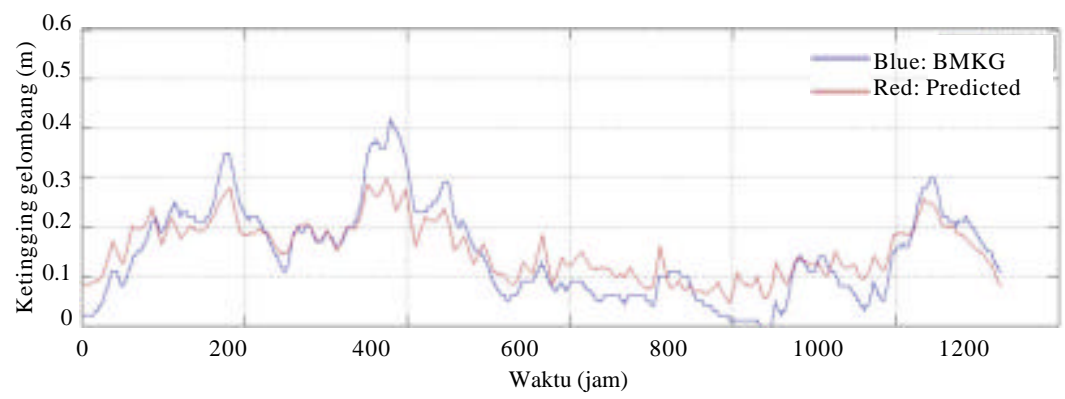

Fig. 9: Wave height prediction Surabaya

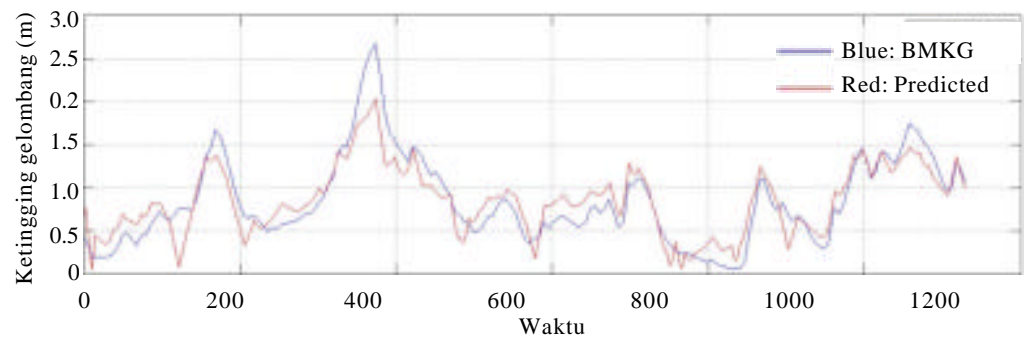

Fig. 10: Wave height prediction Java Sea

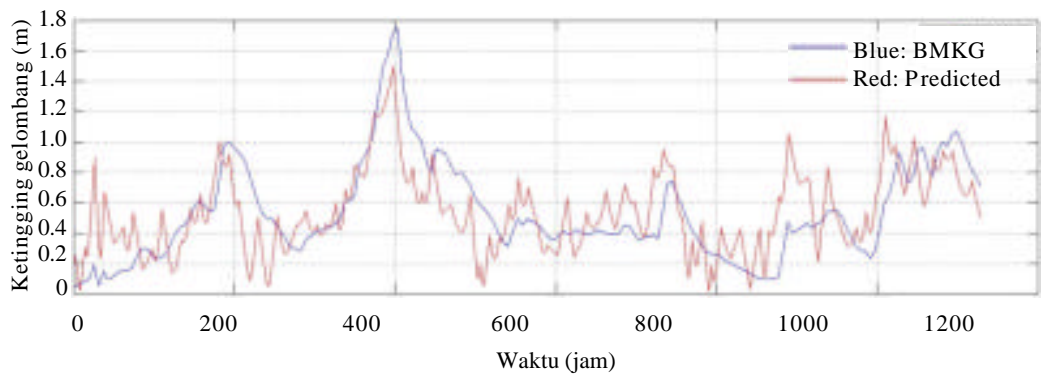

Fig. 11: Waves height prediction Banjarmasin

Table 6: Wave height Banjarmasin

\begin{tabular}{llllll}
\hline Variables & 2006 & 2007 & 2008 & 2009 & 2010 \\
Average & 0.73 & 0.68 & 0.72 & 0.64 & 0.51 \\
Maximum & 2.14 & 2.31 & 1.61 & 1.82 & 1.71 \\
Date 18 January & 3 January & 8 February & 5 February & 13 January \\
\hline
\end{tabular}

wave height $1 \mathrm{~h}$ before. To measure the prediction results whether or not the neural network is used Root Mean Square Error (RMSE). The RMSE is derived from predictive error and data. The smaller the RMSE value, the better the predicted result (Paplinska, 2006). RMSE in Surabaya waters (point A) about 0.04. RMSE at sea of Java (point B) about 0.2 and RMSE in point C about 0.23 . 
Table 7: RMSE validation Jave Sea

\begin{tabular}{|c|c|c|c|c|}
\hline & & & & \\
\hline$\underline{\mathrm{H}}$ & & 10 & 100 & 1000 \\
\hline$\overline{\mathrm{I}}$ & 1 & 0.007859 & 0.007682 & 0.007681 \\
\hline D & 2 & 0.007686 & 0.008701 & 0.008327 \\
\hline D & 3 & 0.007672 & 0.007794 & 0.008398 \\
\hline $\mathrm{E}$ & 4 & 0.007713 & 0.009072 & 0.018973 \\
\hline $\mathrm{N}$ & 5 & 0.007694 & 0.008615 & 0.008247 \\
\hline $\mathrm{L}$ & 6 & 0.007703 & 0.008363 & 0.007882 \\
\hline A & 7 & 0.007673 & 0.008226 & 0.007719 \\
\hline $\mathrm{Y}$ & 8 & 0.007695 & 0.008240 & 0.023369 \\
\hline $\mathrm{E}$ & 9 & 0.007687 & 0.007944 & 0.015568 \\
\hline $\mathrm{R}$ & 10 & 0.007683 & 0.008270 & 0.018127 \\
\hline
\end{tabular}

Table 8: RMSE validation Jave Sea Iteration

\begin{tabular}{llccc}
\hline H & & 10 & 100 & 1000 \\
\hline I & 1 & 0.004735 & 0.004519 & 0.004518 \\
D & 2 & 0.004814 & 0.004051 & 0.004033 \\
D & 3 & 0.004557 & 0.004036 & 0.004033 \\
E & 4 & 0.004572 & 0.004435 & 0.004306 \\
N & 5 & 0.004536 & 0.004474 & 0.004062 \\
L & 6 & 0.004566 & 0.004480 & 0.008119 \\
A & 7 & 0.004503 & 0.004033 & 0.004154 \\
Y & 8 & 0.004511 & 0.004036 & 0.004150 \\
E & 9 & 0.004524 & 0.004039 & 0.004475 \\
R & 10 & 0.004499 & 0.004043 & 0.004008 \\
\hline
\end{tabular}

Table 9: RMSE validation Banjarmasin Iteration

\begin{tabular}{|c|c|c|c|c|}
\hline $\mathrm{H}$ & & 10 & 100 & 1000 \\
\hline I & 1 & 0.006519 & 0.003461 & 0.003460 \\
\hline D & 2 & 0.004662 & 0.003416 & 0.003355 \\
\hline D & 3 & 0.003470 & 0.003404 & 0.004902 \\
\hline $\mathrm{E}$ & 4 & 0.003429 & 0.003418 & 0.003851 \\
\hline $\mathrm{N}$ & 5 & 0.003455 & 0.003436 & 0.003882 \\
\hline $\mathrm{L}$ & 6 & 0.003440 & 0.003397 & 0.004038 \\
\hline A & 7 & 0.003432 & 0.003442 & 0.003556 \\
\hline Y & 8 & 0.003412 & 0.003402 & 0.003998 \\
\hline $\mathrm{E}$ & 9 & 0.003464 & 0.003388 & 0.003485 \\
\hline $\mathrm{R}$ & 10 & 0.003449 & 0.003420 & 0.004104 \\
\hline
\end{tabular}

\section{CONCLUSION}

This research can be concluded, that algorithm neural network influenced by architecture network and input-output. Algorithm neural network the best there are at a point namely by rmse 0.04 . In literature review it was mentioned that the less RMSE, the more both based predictions.

\section{REFERENCES}

Agrawal, J.D. and M.C. Deo, 2004. Wave parameter estimation using neural networks. Mar. Struct., 17: 536-550.

Aisjah, A.S., S. Arifin and W.L. Danistha, 2016. Sverdruv Munk Bretschneider modification (SMB) for significant wave height prediction in Java Sea. Br. J. Appl. Sci. Technol., 16: 1-8.
Akhir, B. and M. Mera, 2011. [Floors of sea waves toward the port of Bengkulu Baai Island (In Indoneshian)]. J. Civil Eng., 7: 47-60.

Arief, H., 2006. [Theory and Application Neural Networks]. CV Andi Offset, Depok, Indonesia, (In Indonesian).

Bhattacharya, B., D.L. Shrestha and D.P. Solomatine, 2003. Neural networks in reconstructing missing wave data in sedimentation modelling. Proceedings of the 30th Congress on IAHR Vol. 500, August 24-29, 2003, IAHR, Thessaloniki, Greece, pp: 770-778.

Deo, M.C. and C.S. Naidu, 1998. Real time wave forecasting using neural networks. Ocean Eng., 26: 191-203.

Dhanistha, W.L., R.A. Atmoko, P. Juniarko and R. Akbar, 2017. Prediction of significant wave height using neural network in the Java Sea (North of Surabaya). Appl. Mech. Mater., 862: 72-77. 
Etemad-Shahidi, A., M.H. Kazeminezhad and S.J. Mousavi, 2009. On the prediction of wave parameters using simplified methods. J. Coastal Res., 1: 505-509.

Gunaydyn, K., 2008. The estimation of monthly mean significant wave heights by using artificial neural network and regression methods. Ocean Eng., 35: 1406-1415.

Jain, P. and M.C. Deo, 2008. Artificial intelligence tools to forecast ocean waves in real time. Open Ocean Eng. J., 1: 13-20.

Londhe, S.N., S. Shah, P.R. Dixit, T.B. Nair and P. Sirisha et al., 2016. A coupled numerical and artificial neural network model for improving location specific wave forecast. Appl. Ocean Res., 59: 483-491.

Makarynskyy, O., D. Makarynska, M. Kuhn and W.E. Featherstone, 2004. Predicting sea level variations with artificial neural networks at Hillarys Boat Harbour, Western Australia. Estuarine, Coastal Shelf Sci., 61: 351-360.

Mandal, S., 2010. Ocean wave prediction using numerical and neural network models. Open Ocean Eng. J., 3: 12-17.

Paplinska-Swerpel, B. and L. Paszke, 2006. Application of neural networks to the prediction of significant wave height at selected locations on the Baltic Sea. Arch. Hydro Eng. Environ. Mech., 53: 183-201.
Paras, M.S., A. Kumar and M. Chandra, 2007. A feature based neural network model for weather forecasting. World Acad. Sci. Eng. Technol., 10: 66-73.

Peres, D.J., C. Iuppa, L. Cavallaro, A. Cancelliere and E. Foti, 2015. Significant wave height record extension by neural networks and reanalysis wind data. Ocean Modell., 94: 128-140.

Srivastava, P.S., 1964. A comparative study of wave forecasting techniques. J. Appl. Meteorol., 3: 206-207.

Sugianto, D.N., 2012. [Model of distribution of wind speed data and its utilization in wave forecasting in the waters of the Paciran Sea, East Java (In Indoneshian)]. Ilmu Kelautan Indonesian J. Mar. Sci., 15: 143-152.

Sugiarto, L., 2012. [Variability of sea waves in the Java Sea and karimata|strait viewed from the meteorological dynamics perspective]. Master Thesis, Universitas Indonesia, Depok, Indonesia. (In Indonesian)

Sutojo, T., S. Si, M. Kom, E. Mulyanto and D.V. Suhartono, 2010. [The Concept of Artificial Intelligence]. Penerbit Andi, Palembang, Indonesia, (In Indonesian).

Triatmodjo, B., 1999. [Beach Technique]. Beta Offset, Yogyakarta, Indonesia, Pages: 397 (In Indonesian). 